\title{
Heat Production, Nerve Function, and Morphology following Nerve Close Dissection with Surgical Instruments
}

\author{
Johan Carlander, C Koch, L Brudin, C Nordborg, Oliver Gimm and K Johansson
}

\section{Linköping University Post Print}

N.B.: When citing this work, cite the original article.

The original publication is available at www.springerlink.com:

Johan Carlander, C Koch, L Brudin, C Nordborg, Oliver Gimm and K Johansson, Heat Production, Nerve Function, and Morphology following Nerve Close Dissection with Surgical Instruments, 2012, World Journal of Surgery, (36), 6, 1361-1367.

http://dx.doi.org/10.1007/s00268-012-1471-x

Copyright: Springer Verlag (Germany) http://www.springerlink.com/?MUD=MP

Postprint available at: Linköping University Electronic Press http://urn.kb.se/resolve?urn=urn:nbn:se:liu:diva-78261 


\section{Heat production, nerve function and morphology following nerve close dissection with surgical instruments.}

Johan Carlander [1], C. Koch [2], L. Brudin [3], C. Nordborg [4], O. Gimm [5,6], K. Johansson [5];

[1] Department of Surgery, Västerås, Sweden. [2] PTB, Braunschweig, Germany.

[3] Department of Clinical Physiology, Kalmar, Sweden. [4] Department of Pathology, Sahlgrenska University Hospital, Göteborg, Sweden. [5] Department of Surgery, County Council of Östergötland, Division of Surgery, and [6] Department of Clinical and Experimental Medicine, Linköping University, Sweden.

The study was supported by the FORSS (Regional South East Swedish Research Fund).

\section{Potential conflicts of interest:}

The authors initiated the study and their respective departments supported their participation. The instruments used in the study were provided for the study by the respective manufacturers (Ethicon Endo Surgery and Valleylab). The study was arranged on the basis of a written contract, prior to the study and independent of the manufacturers of the tested surgical instruments 


\section{Abstract}

\section{Introduction:}

Postoperative nerve dysfunction is a problem in many areas of surgery and may be caused by heat produced by surgical instruments. The aim of this study was to compare an ultrasonically activated instrument (US), monopolar and bipolar electrosurgery (ES) with respect to heat production, nerve function and nerve morphology following in vivo application.

\section{Materials and methods:}

The biceps femoris muscle of anesthetized rats was cut in a standardized manner longitudinally $1 \mathrm{~mm}$ adjacent to the sciatic nerve using US shears, monopolar ES knife or bipolar ES scissors. Activation time and temperature was recorded continuously within 1-4 $\mathrm{mm}$ of the activation site ipsi- and contralateral to the nerve using two thermoelectric microsensors designed for application in tissue. Temperature rise and time delay of reaching the temperature maximum, as an expression of heat spread within tissue, maximum temperature and thermal dose (equivalent time of exposure at 43 degrees $\mathrm{C}$ ) were measured and calculated. A total of 49 functional experiments were conducted. The electromyographic (EMG) potential was recorded distally before and after each experiment. Nerve dysfunction was defined as more than 10 per cent loss of the evoked EMG potential. Forty-eight nerves were coded and submitted to blind histopathological examination and morphological damage was graded on a 4-grade scale.

\section{Results:}

The maximum temperature elevation and the thermal dose was significantly higher for the bipolar ES compared with the US instrument $(\mathrm{p}=0.024, \mathrm{p}=0.049)$, and with much less variation of results for the US instrument. The monopolar ES maximum temperature and 
thermal dose were lower but a very large variation occurred probably due to more random electrical spread to the ground electrode and muscle motion artefacts making the comparison of results unreliable. Functional loss was least common in the US group without being significant compared to bipolar and monopolar ES $(\mathrm{p}=0.11, \mathrm{p}=0.10)$. Moderate and severe morphological damage was significant less common in the US group compared to the monopolar ES group $(\mathrm{p}=0.01)$. We found no correlation between the highest temperatures and the degree of morphological damage.

\section{Conclusion:}

The temperature elevation depends strongly on the distance to the activated instrument. The bipolar ES scissors generates a higher maximum temperature and thermal dose with a greater variation in than the US. Functional loss and severe morphological damage was uncommon in all groups.

\section{Keywords:}

Surgical dissection devices, thermal dose, iatrogenic nerve injury 


\section{Introduction}

Nerve protection requires knowledge about and proper identification of the relevant surgical planes and nerve structures and a careful technique for avoiding traction and compression. In addition, activation of heat generating devices close to the nerves should be avoided. The extent and risk of lateral spread of heat during usage of different surgical devices is still not entirely investigated.

Tissue coagulation occurs when the temperature rises above $45^{\circ} \mathrm{C}(1-3)$. When temperature rises higher than that, proteins starts to denaturize and cells die at temperatures between 60-80 ${ }^{\circ} \mathrm{C}(4)$.

Monopolar and bipolar electrosurgery (ES) are the most commonly used techniques that combines cutting with coagulation for haemostasis. New versions of ES generators have been improved by impedance sensors that regulate the energy delivery, in order to reduce risk of collateral heat damage. Ultrasonically activated instruments (US) provide an alternative technique for cutting and coagulation using high frequency vibration of the active blade.

Previous studies, often using thermo cameras, have shown that US disperse less heat to the surrounding tissue during dissection compared to ES $(5,6)$ and US have been claimed to be safer than traditional diathermy (7). The thermal properties of living biological tissues are not well known $(8,9)$, and experiments on thermal spread in vivo are scarce.

In an earlier study with the same rat model (10), we compared monopolar and bipolar ES and US with respect to EMG-function and light microscopy morphology after nerve close 
activation. We found a significant reduction in the EMG potential in the monopolar ES group compared with the US group and morphological examination also showed significant less nerve damage in the US group. We did not perform any temperature measurements in that study.

The aim of this study was to accurately measure the temperature elevation and time duration (thermal dose) during activation of ES and US close to the nerve in vivo and to simultaneously study nerve function and morphology. 


\section{Materials and methods}

The study involved 25 Sprague-Dawley rats weighing 285-495 grams. The range of bodyweight was similar in the experimental groups. The rats were anaesthetized with ketamine $70 \mathrm{mg}$ per $\mathrm{kg}$ bodyweight and xylazine $5 \mathrm{mg} / \mathrm{kg}$, and were maintained on spontaneous ventilation. Each sciatic nerve was exposed by separation of the biceps femoris and the tensor fascia lata muscles. During the dissection, the surgeon's hand rested on the table, the rat's leg was stabilized, and the distances between the nerve and the activated instruments were checked with a microscope and millimetre paper. Two surgeons performed the dissections under a infra red lamp. The following instruments and settings were used: monopolar ES (Valleylab, Force XL) at power setting $30 \mathrm{~W}$, bipolar ES (PowerStar* Fine, Ethicon) at power setting 30W and US instruments (CS shears; Ethicon) at power setting 3. These were the settings recommended by the manufacturers and are commonly used in clinical practice. At the end of the procedure, the animals were killed by intracardiac injection of potassium chloride solution.

One surgical procedure was performed on each leg. A 5-mm longitudinal incision was made immediately adjacent to the nerve (within $1 \mathrm{~mm}$ ) with a monopolar ES knife, bipolar ES scissors or US shears.

\section{Temperature studies}

The temperature increase was measured with thermoelectric sensors designed for an application in tissue [Koch 2003] based on a thermistor in which electrical resistance was dermined.(Fig1). The ipsilateral sensor was marked green and the sensor contralateral to the 
nerve/activated instrument was marked black. To make a measurement, the tissue was pierced and the sensor was inserted down to the measurement position, on each side of the nerve.

The distance between the sensors was about 3-4 $\mathrm{mm}$. The temperature sensors were calibrated prior to the use in tissue. For this purpose they were immersed in a water bath. The water was continuously stirred and the temperature was controlled by a servo system and measured with a calibrated reference thermometer.

The distances $\mathrm{d}$ from the blade were set using millimetre paper and a microscope, but because of tissue movement the actual value could be exactly determined only afterwards by a ruler to each sensor. The electrical resistance of the sensors was measured by digital meters (Keithley 2000 and 2700) and a computer acquired the data. The minimum sampling time was $80 \mathrm{~ms}$ and the two sensors could be read simultaneously.

The temperature $(\mathrm{T})$ was continuously recorded during activation and the maximum values were determined after the measurement had been completed.

The thermal dose, being the most generally accepted concept for estimating temperaturerelated tissue damage threshold, was calculated as a product of temperature elevation and duration of exposure at each temperature level using a temperature dependent weighting function (11: Sapareto S.A, Dewey W.C (1984). Thermal dose determination in cancer therapy. Int J Rad Onc Biol Phys 10; 787-800)

During evaluation of the data it became obvious that the distance measurement before and after activation of the instrument could only be carried out with large uncertainty in relation to the starting time. An alternative choice for a variable relating to distance properties was the 
delay of the moment when the highest temperature is reached with respect to the starting time. The heat needs more time to come to a fixed point the larger the distance is. (Fig 2)

\section{Functional studies}

The dissected sciatic nerve was divided proximally and mounted on to a pair of silver hook electrodes for stimulation. The motor response (electromyographic (EMG) potential) was continuously recorded distally by a unipolar stainless steel needle electrode (diameter 0.6 $\mathrm{mm}$ ) inserted into the foot muscles. A second needle was inserted $1 \mathrm{~cm}$ distal to the recording electrode as a reference electrode. Muscle response was measured before and after the surgical procedures using repeated stimulation with a $2-\mathrm{Hz}$ square wave and $0.5-\mathrm{ms}$ pulses. The stimulation intensity was adjusted to achieve maximal muscle responses. Because the state of the stimulated nerve and the positions of the electrodes could not be identical for each nerve, the threshold of muscle responses, defined by the start of muscle twitching, required three to five times the threshold intensity $(0 \cdot 5-1 \mathrm{~mA})$ to get maximal M-responses. Each muscle response was amplified and recorded continuously on a chart recorder. Four to five maximal muscle responses of equal amplitude were printed out before and after each surgical procedure for subsequent off-line analysis of nerve function.

The EMG potentials were recorded for 49 nerves. Nerve dysfunction was defined as greater than 10 per cent height reduction in the EMG potential evoked after the surgical procedure compared with that evoked before the procedure.

\section{Morphological studies}


Nerve tissue was collected for histological and morphological examination after the above experiments. Forty-eight nerves were studied after longitudinal incision. Two nerves that were cut out with normal scissors were used as controls for the morphological study.

The nerve sections, which were about $10 \mathrm{~mm}$ long, were removed without touching the site of dissection, fixed to cork, and then stored in 4 per cent paraformaldehyde. After fixation in 1 per cent osmium solution, the nerves were dehydrated in alcohol (70 per cent for $1 \mathrm{~h}, 95$ per cent for $2 \mathrm{~h}, 100$ per cent for $1 \mathrm{~h}$ ) and preinfiltrated in equal amounts of 100 per cent alcohol and plastic (Technovit 7100)• without hardener for $2 \mathrm{~h}$. The following day, the nerves were imbedded in plastic and hardener. After sectioning, the specimens were stained with haematoxylin and eosin and mounted with Pertex. Serial sections were made in distal and proximal directions, starting from the central section of the nerve that had been adjacent to the activated surgical tool. Five to six serial sections were made from each location, with $100 \mu \mathrm{m}$ between each location. Nerve tissues were coded and submitted to blind histopathological examination by a pathologist with extensive experience in nerve pathology. The section of best technical quality at each location was judged and the most severe injury noted was taken as the result. The slides were examined with a light microscope at a total magnification of $400 \times$ to assess the degree of nerve injury. The degree of injury was graded on a 4-grade scale. Normal, myelin free from vacuoles and no apparent thickening of the myelin sheath; slight injury, small myelin vacuoles and no apparent thickening of the myelin sheath; moderate injury, obvious vacuolization and swelling with thickening of the myelin sheath, causing encroachment on the axon; and severe injury, coagulated fibres with myelin sheaths that were markedly thickened, homogeneous and pale. The percentage of the aerial damage was noted.

The study was approved by the Animal Care Committee, Linköping University, Sweden. 


\section{Statistical analysis:}

Group differences were tested as follows. Parameters showing almost identical mean values for two of the three groups were lumped together and tested against the third group to increase the statistical power using Mann-Whitneys U-test. Remaining parameters were analysed using Kruskal-Wallis non-parametric ANOVA followed by Mann-Whitneys U-test in case of significance. $\mathrm{P}<0.050$ was considered to be significant. 


\section{Results}

\section{Thermal results}

Combined data from both sensors are presented in Table 1.

The maximum temperature elevation and thermal dose was significantly higher for the bipolar ES compared with the US instrument ( $\mathrm{p}=0.024, \mathrm{p}=0.049)$. The spread of heat (Time delay) in the tissue were significant lower for US, compared to Bibolar and Monopolar ES ( $p=0,006$, $\mathrm{p}=0,015)$.

Although the monopolar ES showed the lowest temperature elevation and doses in the experiments, the spread of the values were always the largest.

Separate data from the ipsilateral green sensor, being closest to the activated instrument, as the maximum temperature elevation and thermal dose were significantly higher for the bipolar ES compared with the US instrument, in lower time delays, and with much less data variation for the US instrument (Fig 3-4). This difference was significant both, when the distance was estimated by visual mm-scale and when the time delay was used as a more objective parameter for the distance (Fig 7-10).

The monopolar ES induced maximum temperature and thermal dose values were lower but showed very large variation. This was statistical significant over the whole range.

Separate data for the black sensor, positioned contralateral to the nerve and the activated instrument, showed that no significant difference could be recorded between the instruments with respect to maximal temperature or thermal dose. Again the monopolar ES showed the lowest values with the widest confidence ranges. 
We found no correlation between the highest temperatures measured and morphological damages.

\section{Functional results}

The measurement of EMG potentials after nerve close dissection showed that loss was generally infrequent in all groups and were least common in the US group without being significant compared to both bipolar and monopolar ES $(p=0.11, p=0.10)$. Nerve injury was defined as more than 10 per cent height reduction of the evoked electromyographic potential (Table 1).

\section{Handheld experiments}

In all reliable measurements $100 \%$ nerve potential was found except in one case where $0 \%$ was measured. This case showed the highest dose $\left(5 \times 10^{5} \mathrm{~min}\right)$ and also the highest maximum temperature elevation. One experiment with only slightly less dose $\left(3.3 \cdot 10^{5} \mathrm{~min}\right)$ yielded however full nerve potential. Several experiments in the range of $1 \cdot 10^{3} \min$ to $1 \cdot 10^{4}$ min showed also full nerve potential. Without any statistical prove it can be concluded as a trend that the nerve tolerates a dose of at least $1 \cdot 10^{4} \mathrm{~min}$.

\section{Morphological results}

Moderate and severe morphological damage was significant less common in the US group compared to the monopolar ES group $(\mathrm{p}=0.01)$ (Table1). Normal morphology was seen in the control nerves. 


\section{Discussion}

The presence of objective data comparing the safety of heat spread in in vivo experiments is limited. Iatrogenic nerve injury is a significant problem in many areas of surgery, and our study focused on the risk of collateral nerve injury.

In this study exact activation times and an indirect distance estimation (time delay) was used to get accurate measurements of maximum temperature elevation and thermal doses in transacted tissue.

The bipolar ES scissors generates a higher maximum temperature and thermal dose with a greater variation than the US. This was most significant with the sensor closest to the activated instrument and in the combined data from both sensors. The monopolar ES generated lowest temperatures and thermal doses, but showed always the largest confidence ranges and motions artefacts during the experiments with the monopolar ES made the data unreliable??

Functional loss and severe morphological damage was uncommon in all groups despite activation of the instruments very close to the nerves in our experimental set-up. Without any statistical prof, the handheld experiments indicated that the isciatic nerve tolerates a dose of at least $1 \cdot 10^{4} \mathrm{~min}$.

In the last years several papers have addressed the thermal properties and lateral thermal spread of surgical instruments $(11,12)$. However, thermal properties of biological tissues are 
not very well known. Prior studies have described higher peripheral thermal energy spread in non-vascularised tissue (13). In vitro studies are probably not fully relevant to the clinical application as the locally produced heat will be transported by the circulating blood and often they are carried out at lower temperatures than in normal body temperatures. The lateral temperature values and thermal doses in the tissues depend strongly on the distance to the blade and the time of exposure for each device. Chemical composition and physical properties of the transacted tissue influence the thermal spread, where thermal measurements show that subcutaneous fat has the lowest thermal conductivity, while muscle gives the highest values (14).

The ES and US instruments work with different physical properties.

The US instruments employs mechanical energy transmitted and amplified at a high frequency such that at the tip of the blade longitudinal motion frequency reaches 55,500 cycles/s. This rapid movement creates temperatures at that proteins denature creating an area of coagulation and allowing concurrent cutting. This cutting and coagulation occurs with a reduced rise in temperature at the tissue level, with less smoke formation, no muscular stimulation and without the transmission of an electric current through the patient. Our data are in accordance with prior studies that have concluded that US instruments spread less thermal energy to surrounding tissue during activation, and that the risk to cause collateral thermal damage is though to be smaller $(13,15-16)$.

Other studies have also described the risk of inadvertent damage to nearby structures due to lateral spread of thermal energy using electrosurgery $(17,18)$, where one study concluded that the monopolar ES generated the highest temperature that resulted in highest lateral thermal spread (11). 
With the bipolar ES the two tines of the forceps perform the active and return electrode functions so that only the tissues grasped is included in the electrical circuit and the loss of thermal energy is restricted to a smaller area. The modern electric cautery generators sense the tissue impedance in order to reduce the risk of lateral thermal damage, although this does not protect from excessive heat production in tissue.

Conventional ES tissue resection occurs at temperatures $>100^{\circ} \mathrm{C}$, primarily through water vaporization (19), extreme local heat is produced when the electric energy meets resistance at the electrode-tissue interface.

In this study bipolar ES scissors generated a significant higher maximum temperature and thermal dose with a greater variation in temperature than the US. This was significant both in the sensor closest to the activated instrument (green sensor) and in the combined data from both sensors. The confidence range in the case of the US was smallest in all experiments which can be advantageous in respect to safety, in order to reliable predict the risk of lateral thermal damage to tissue.

Although the monopolar ES showed the lowest temperature elevation and doses in the experiments, the spread of the values was always the largest. An explanation for this can be the influence of motion artefacts, but also that the ground electrode is connected to the body and the way of the current is not specified and depends on random conditions.

As been shown earlier (17) the temperature elevation in our study was higher at the sensor closest to the activation site, and was achieved in a shorter period of time, compared to the 
black sensor. The time of thermal spread in the tissue took significant longer with the US compared both with the Bipolar and Monopolar ES, this is probably due to its alternate way of dissecting tissue.

In summary, our study indicate a higher grade of safety for activation of the US shears close to nervestructure compared to ES scissors, and could be help in the clinical practise, in order to help users to understand the risk of the devices .

Despite our experimental setup, where the instruments were activated very close to the sciatic nerve, functional loss and severe morphological damage was uncommon in all groups. The results of our study could be help in the clinical practise, in order to help users to understand the risk the devices have, that are used in the operating rooms.

Bygg en hypotes utifrån våra resultat Vad är mest significanta resultatet i studien 


\section{References}

1: Ahlering TE, Eichel L, Chou D, et al (2005) Feasibility study for robotic radical prostatectomy cautery free neurovascular bundle preservation. Urology 65: 994-997

2: Zohar Y, Sadov R, Strauss M, et al (1996) Ultrastructural study of peripheral nerve injury induced by monopolar and bipolar diathermy. Ann Otol Rhinol Laryngol 105: 673-677

3: Wondergem J, Haveman J, Rusman V, et al (1988) Effects of local hyperthermia on the motor function of the rat sciatic nerve. In J Radiat Biol 53: 429-438

4: Kunde D, Welch C (2003) Ultracision in gynaecological laparoscopic surgery. J Obstet Gynaicol 23: 347-352

5: Perko Z, Pogorelic Z, Bilan K, et al (2006) Lateral thermal damage to rat abdominal wall after harmonic scalpel application. Surg Endosc 20: 322-324

6: Sietes C, Eijsbouts QAJ, von Blomberg BME, et al (2001) Ultrasonic energy vs. monopolar electrosurgery in laparoscopic cholecystectomy: influence on the postoperative systemic immune response. Surg Endosch 15: 69-71

7: Diamantis T, Kontos M, Arvelakis A, et al (2006) Comparision of monopolar electrocoagulation, bipolar electrocoagulation, Ultracision and Ligasure. Surg Today 36: 908913

8: Duck FA, Physical Properties of Tissue (1991) In: A Comprehensive Reference Book (London: Academic Press)

9: Olsrud J, Friberg B, Ahlgren M, et al (1998) Thermal conductivity of uterine tissue in vitro. Physics in medicine an Biology 43: 2397-2406

10: Carlander J, Johansson K, Lindström S, et al (2005) Comparison of experimental nerve injury caused by ultrasonically activated scalpel and electrosurgery.

Br J Surg 92: 772-777

11: Sutton PA, Awad S, Perkins AC, et al (2010) Comparison of lateral thermal spread using monopolar and bipolar diathermy, the Harmonic Scalpel and the Ligasure.

Br J Surg 97: 428-433

12: Campbell PA, Cresswell AB, Frank TG, et al (2003): Real-time thermography during energized vessel sealing and dissection. Surg Endosc 17: 1640-1645

13: Phillips CK, Hruby GW, Durak E, et al (2008): Tissue response to surgical energy devices. Urology 71: 744-748

14: El-Brawany M.A, Nassiri D.K, Terhaar G, el al (2009) Measurement of thermal and ultrasonic properties of some biological tissues. J Med Eng Technol 33: 249-256 
15: Eman TA, Cucschieri A (2003) How safe is high power Ultracision dissection. Ann Surg 237: 186-191

16: Pogorelic Z, Perko Z, Druzijanic N, et al (2009) How to prevent lateral thermal damage to tissue using the harmonic scalpel: Experimental study on pig small intestine and abdominal wall. Eur Surg Res 43: 235-240

17: Koch C, Friedrich T, Metternich F, et al (2003) Determination of temperature elevation in tissue during the application of the harmonic scalpel.

Ultrasound Med Biol 29: 301-309

18: Humes DJ, Ahmed I, Lobo DN (2010) The pedicle effect and direct coupling: delayed thermal injuries to the bile duct after laparoscopic cholecystectomy. Arch Surg 145: 96-98

19: Razvi H, Perlmutter AP (1996) Laser-tissue interactions during laser prostatectomy. Urology 48: 133-134 


\section{Table/figures}

\begin{tabular}{|c|c|c|c|c|c|c|c|}
\hline & $\begin{array}{l}\text { Monopolar } \\
\text { ES }(n=18)\end{array}$ & $\begin{array}{c}\text { Bipolar ES } \\
(\mathrm{n}=16)\end{array}$ & $\begin{array}{c}\mathbf{U S} \\
(\mathrm{n}=15) \\
\end{array}$ & & & & \\
\hline & Mean () & Mean () & Mean () & $\mathrm{p}^{*}$ & $\mathrm{p}^{* *}$ & $\mathrm{p}^{* * *}$ & $\mathrm{p} * * * *$ \\
\hline $\begin{array}{c}\text { Max Temp } \\
\text { (T max) }\end{array}$ & $\begin{array}{l}38,9(32,1- \\
69,7)\end{array}$ & $\begin{array}{l}55,6(35,9- \\
73,6)\end{array}$ & $\begin{array}{l}39,6(29,0- \\
61,2\end{array}$ & 0,007 & 0,597 & 0,041 & 0,064 \\
\hline $\begin{array}{c}\text { Max } \\
\text { Tempelevation } \\
(\Delta \mathrm{T} \text { max })\end{array}$ & $\begin{array}{l}9,1(1,5- \\
41,1)\end{array}$ & $\begin{array}{l}26,8(3,8- \\
44,6)\end{array}$ & $\begin{array}{l}12,0(1,4- \\
31,7)\end{array}$ & 0,032 & 0,022 & 0,762 & 0,024 \\
\hline Thermal dose & $\begin{array}{l}-1,0(-8,5- \\
18,7)\end{array}$ & $\begin{array}{l}8,2(-5,7- \\
21,2)\end{array}$ & $\begin{array}{l}1,1(-8,7- \\
13,1)\end{array}$ & 0,030 & 0,014 & 0,509 & 0,049 \\
\hline $\begin{array}{c}\text { Time delay } \\
(\Delta \mathrm{t} \text { max })\end{array}$ & $\begin{array}{l}9,4(-9,4- \\
34,5)\end{array}$ & $\begin{array}{l}11,7(5,1- \\
62,9)\end{array}$ & $\begin{array}{l}20,3(13,7- \\
87,6)\end{array}$ & 0,009 & 0,297 & 0,006 & 0,015 \\
\hline $\begin{array}{c}\text { EMG- } \\
\text { Potential, \% }\end{array}$ & $60,6(47,6)$ & $62,5(47,8)$ & $88,7(28,0)$ & 0,188 & & & \\
\hline Morfphogi, \% & $\begin{array}{l}39,2(10,0- \\
56,7)\end{array}$ & $\begin{array}{l}42,5(4- \\
86,7)\end{array}$ & $\begin{array}{l}32,5(0,0- \\
63,3)\end{array}$ & 0,077 & 0,597 & 0,041 & 0,064 \\
\hline
\end{tabular}

Table 1: Combined data from both thermo sensors

*) Kruskal-Wallis ANOVA by ranks

**) Mann-Whitney U-test: Monopolar ES vs bipolar ES

***) Mann-Whitney U-test: Monopolar ES vs US

****) Mann-Whitney U-test: Bipolar ES vs US

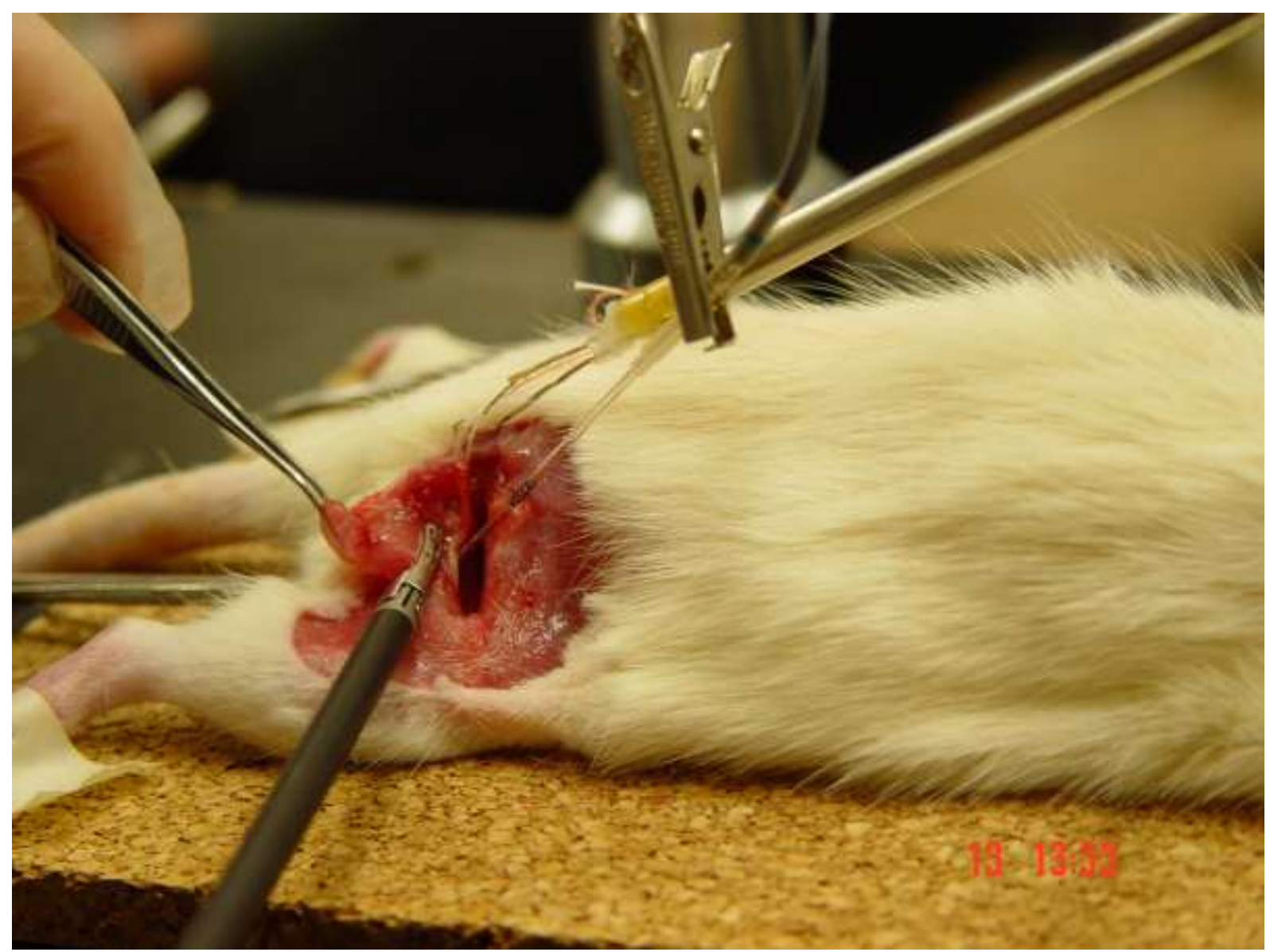

Fig 1: Set up of the experiments 


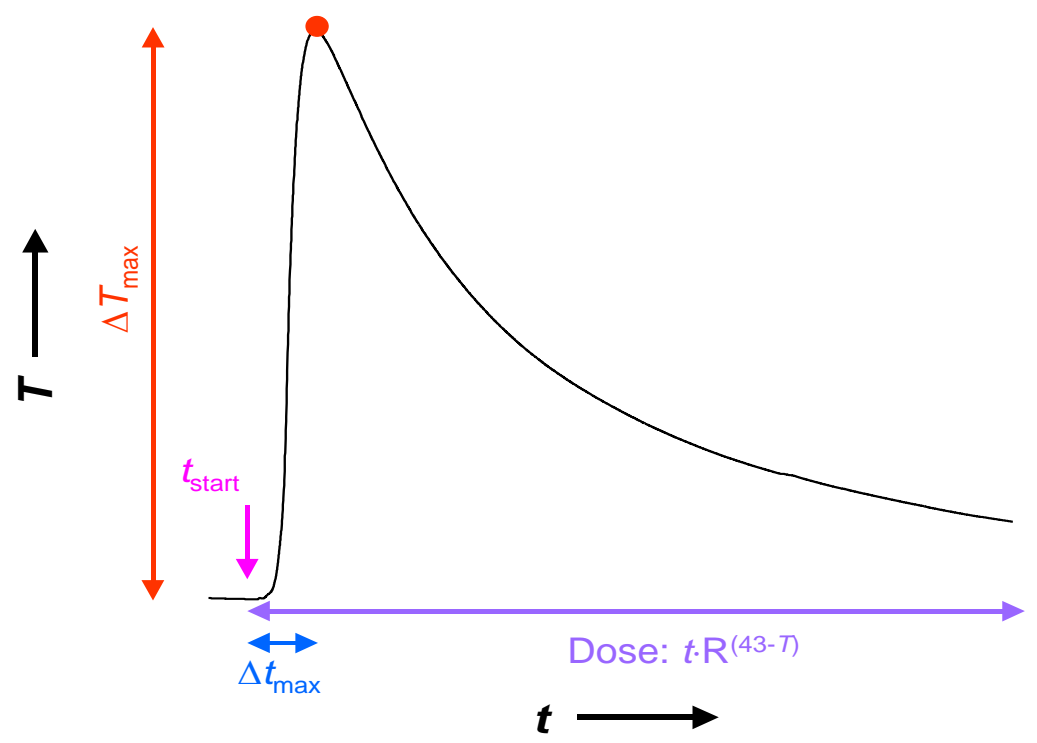

Fig. 2: Typical temperature-time dependence obtained from the measurements, parameters given as described in the text

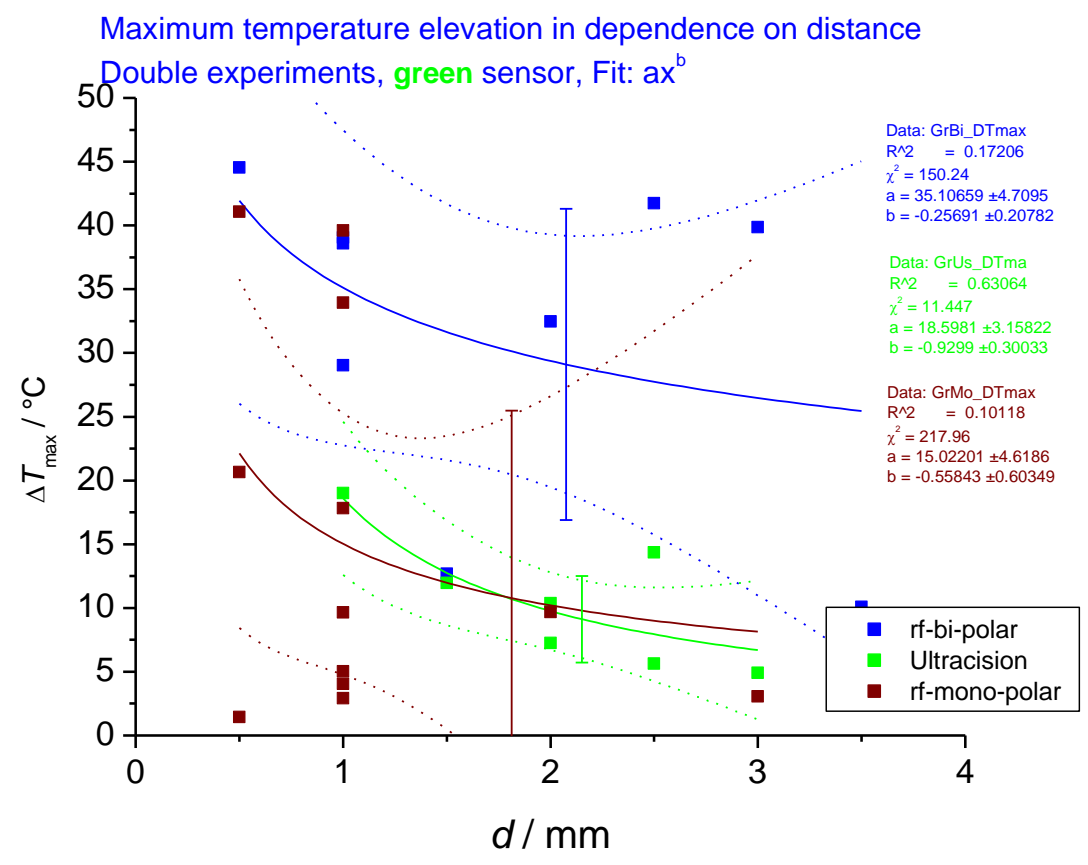

Fig 3: Dependence of maximum temperature on distance for the green sensor. The dashed lines give the $90 \%$ confidence ranges for the fitting procedure. 


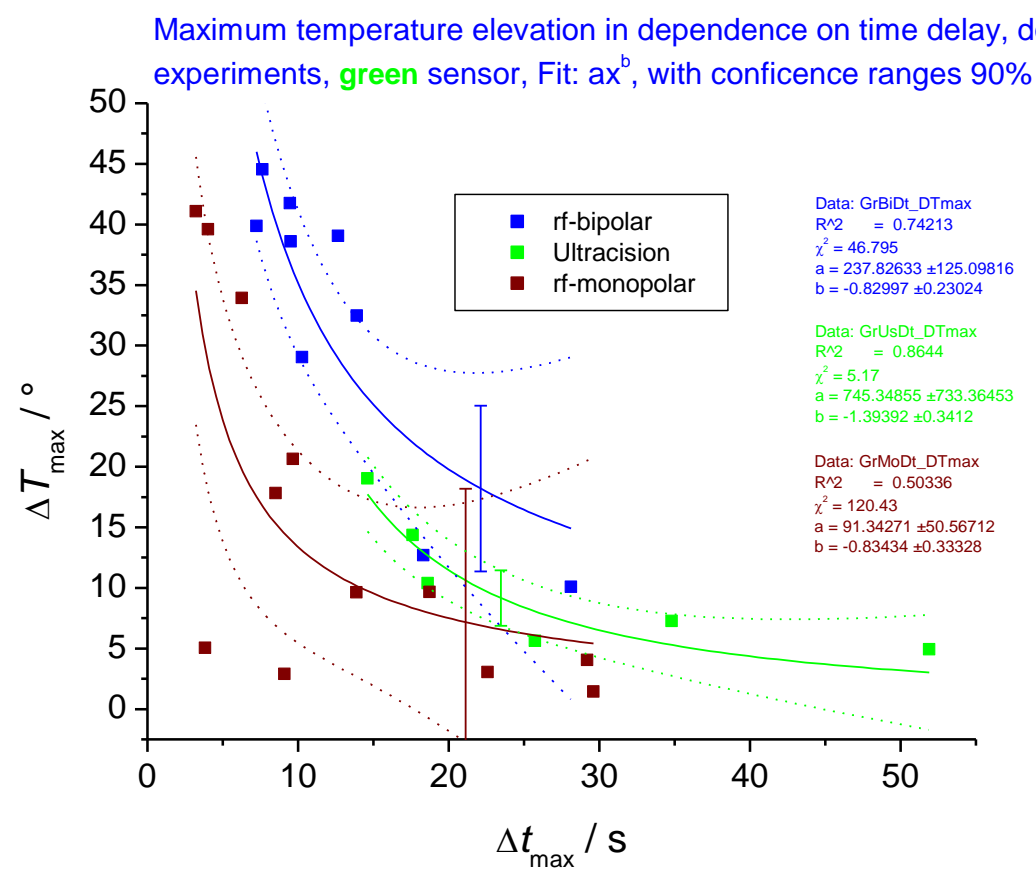

Fig 4: Dependence of maximum temperature on time delay for the green sensor. The dashed lines give the $90 \%$ confidence ranges for the fitting procedure.

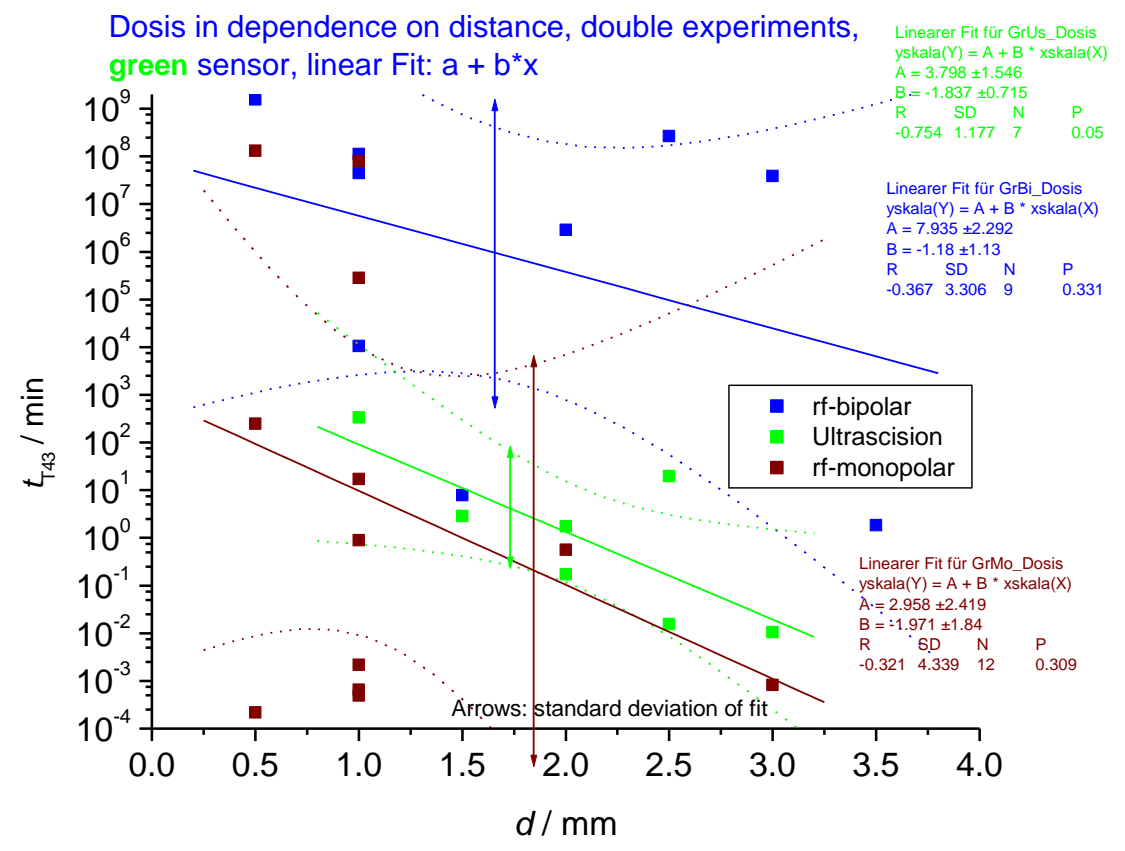

Fig 5: Dependence of dose on distance for the green sensor. The dashed lines give the $90 \%$ confidence ranges for the fitting procedure. 


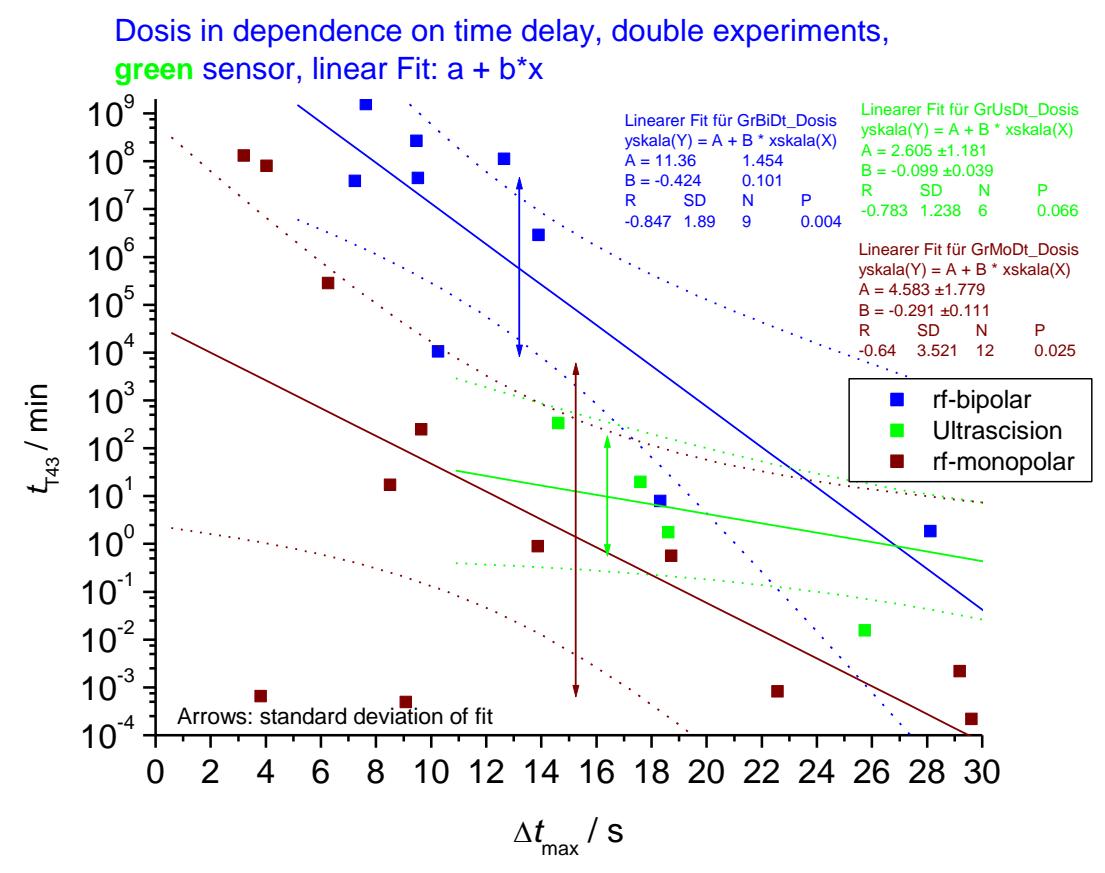

Fig 6: Dependence of dose on time delay for the green sensor. The dashed lines give the $90 \%$ confidence ranges for the fitting procedure. 